\title{
BODY MASS INDEX AND BLOOD PRESSURE RESPONSE TO PEAK EXERCISE IN YOUNG MALES
}

\author{
K. Venkata Sai ${ }^{1}$, P. Venkateswara Rao ${ }^{2}$, A. Hemalathadevi ${ }^{3}$, V. Srinivasu ${ }^{1}$ \\ ${ }^{1}$ SIMS College of Physiotherapy, Guntur, Andhra Pradesh, India. \\ ${ }^{2}$ P.Venkateswara Rao, Department of Anatomy, Katuri Medical College, Guntur, India. \\ ${ }^{3}$ A. Hemalathadevi, Department of Physiology, Siddhartha Medical College, Vijayawada, India. \\ ${ }^{1}$ V.Srinivasu, Principal, SIMS College of physiotherapy, Guntur, Andhra Pradesh, India.
}

\section{ABSTRACT}

Background: Obesity is a potential risk factor for development of various cardiovascular diseases. Blood pressure response to exercise has been an indicator for developing hypertension. This study is intended to study the effect of body mass index on blood pressure response to peak exercise.

Material and methods: This study was carried out with ninety young healthy males ( 30 normal weight, 30 overweight, 30 obese) of age group 18-22 years. Peak exercise was performed on treadmill using Bruce protocol. Blood pressure was measured at baseline and at exhaustion. Statistical analysis was done using one way ANOVA.

Results: The obese group showed higher resting systolic blood pressure compared to normal weight group (115.86 +9.1 vs. $106.32+8.41)$. At exhaustion there is increased systolic blood pressure in obese group compared to normal weight group $(155.76+14.70$ vs. $135.80+10.01)$ as a result of cardiac overload. Diastolic blood pressure in obese group reduced to a greater extent when compared to normal weight group but was not statistically significant.

Conclusion: Exacerbated blood pressure response to peak exercise among obese young males suggests greater reactivity to physical exertion and risk of developing hypertension.

Keywords: BMI, Peak exercise, Blood Pressure, Obese.

\section{INTRODUCTION}

Globally, there is an increase in the prevalence of overweight and obesity among adolescent and youth. In south India this prevalence is raising at a faster pace [1-3]. The reason for this could be due to lack of physical activity and increased consumption of high calorie food. A very near association was seen between obesity and exaggerated blood pressure which could be attributed to increased activity of sympathetic nervous system in renal and peripheral soft tissue and increased activity of reninangiotensin-aldosterone system [4] .The blood pressure response during exercise test is a useful tool for assessing cardiac status of the individual. Abnormal increase or decrease of blood pressure in response to exercise is a valid risk factor for developing cardiovascular diseases in future. In past, various studies were done to find out hemodynamic

*Corresponding author: Email: saee29@gmail.com

http://dx.doi.org/10.20530/IJTA $33 \quad 9-12$ ISSN 2320-138X (c) 2016 responses to isometric exercises and thread mill exercise in adolescent and teen population [5-8]. However, there is very scanty and conflicting information available about blood pressure response to peak exercise in overweight and obese Indian youth. Therefore, this work was intended to study the effect of $\mathrm{BMI}$ on blood pressure response to peak exercise in young healthy males.

\section{MATERIALS AND METHODS}

One hundred twenty healthy male students were selected according to the eligibility criteria. The inclusion criteria were 1 ) Healthy male students of age between 18 to 22 years 2) Not undergoing any physical conditioning programme 3 ) willingness to participate in the study. Exclusion criteria were 1) History of hypertension 2) history of cardiac or lung diseases 3)habit of smoking 4) alcohol consumption 5) usage of cardiovascular or respiratory system affecting drugs. The weight and height of every student was measured in order to calculate the Body Mass Index (BMI). Depending on the BMI recorded, subjects were divided into normal weight group (BMI 18 to $22.9 \mathrm{~kg} / \mathrm{m}^{2}$ ), overweight group (BMI $\geq 23$ to $24.9 \mathrm{~kg} / \mathrm{m}^{2}$ ) and obese group (BMI $\geq 25$ 
$\left.\mathrm{kg} / \mathrm{m}^{2}\right)$.The BMI cut off point used for this purpose was in accordance with those suggested for Indian population[9].

This study was approved by institutional ethical committee. All participants were informed about the purpose and proper explanation was given regarding the procedures used in the study. Verbal and written consents were taken. The peak exercise was performed on motorized treadmill using Bruce protocol as per AHA/ACC guidelines [10, 11].The participants were instructed to walk or run till maximum of their ability until they got exhausted and can no more go on with the exercise. The participants were asked for any discomfort experienced for every two minutes of exercise. The blood pressure was measured initially before commencement of the exercise and at the point of exhaustion using automatic BP apparatus. The baseline physical characteristics and blood pressure changes to peak exercise among the three groups were analyzed using one-way ANOVA to detect the significance of differences. Data analysis was done using SPSS software.

\section{RESULTS}

Among one hundred twenty healthy male participants who met the eligibility criteria, ninety of them (30 normal weight, 30 overweight, 30 obese) were included in the study. The baseline characteristics of all the three groups were summarized in Table 1 and Table 2. All the three groups were well matched with respect to age. Weight, height and BMI showed significant difference between normal weight group and obese group at baseline.

Resting mean level systolic blood pressure among obese group was significantly higher than normal weight group. No significant difference was found between overweight and obese as well as normal weight and overweight groups. Resting diastolic blood pressure between obese and overweight groups was significantly higher than normal weight group. No significant difference was found between overweight and obese groups. At exhaustion the systolic blood pressure was significantly higher in overweight and obese groups when compared to normal weight group. Diastolic blood pressure was reduced in overweight and obese groups when compared to normal weight group but statistical significance was not obtained.

\section{DISCUSSION}

With the increasing prevalence of obesity among Indian youth, the government of India had done various surveys regarding body mass index and has reduced the diagnostic cut off to $23 \mathrm{~kg} / \mathrm{m} 2$ as opposed to $25 \mathrm{~kg} / \mathrm{m} 2$ to fight against obesity [9].Utilizing these recently proposed BMI cut off points study was done to find out and compare blood pressure changes to peak exercise among obese, overweight and normal weight participants. The results obtained in the study showed that the resting systolic blood pressure was higher in overweight and obese participants. Similar findings were obtained by various other studies [12-14]. Various factors concerned with increase of blood pressure in obesity includes increased blood volume and cardiac output in response to increased metabolic demand induced by excess body weight. At exhaustion the systolic blood pressure response was significantly higher when compared to normal weight group. This could be attributed to increased peripheral vascular resistance and exacerbated sympathetic activity that contributes primarily in maximal exertion, when the mechanisms of metabolic and mechanical feedback of active muscles and joints trigger a significant increase in

TABLE 1: Physical characteristics among three groups

\begin{tabular}{lcccc}
\hline PARAMETER & $\begin{array}{c}\text { NORMAL WEIGHT } \\
(\mathbf{n}=\mathbf{3 0})\end{array}$ & $\begin{array}{c}\text { OVER WEIGHT } \\
(\mathbf{n}=\mathbf{3 0})\end{array}$ & $\begin{array}{c}\text { OBESE } \\
(\mathbf{n}=\mathbf{3 0})\end{array}$ & P value \\
\hline AGE $(\mathrm{Yrs})$. & $19.46 \pm 1.25$ & $19.56 \pm 1.05$ & $19.6 \pm 1.17$ & 0.9649 \\
Weight $(\mathrm{Kg})$ & $50.96 \pm 4.3$ & $67.43 \pm 4.26^{*}$ & $81.16 \pm 6.25+\ddagger$ & $<0.05$ \\
Height $(\mathrm{m})$ & $1.56 \pm 0.04$ & $1.68 \pm 0.06^{*}$ & $1.66 \pm 0.03 \dagger$ & $<0.05$ \\
BMI $\left(\mathrm{Kg} / \mathrm{m}^{2}\right)$ & $20.92 \pm 1.13$ & $23.78 \pm 0.56^{*}$ & $29.15 \pm 2.3 \dagger \ddagger$ & $<0.05$ \\
\hline
\end{tabular}

The level of significance was set at $p<0.05$

Values expressed as Mean \pm SD

* Significantly different between normal and overweight group

tSignificantly different between normal and obese group

$\ddagger$ Significantly different between overweight and obese group 
TABLE 2: Blood pressure changes to peak exercise among three groups

\begin{tabular}{lcccc}
\hline PARAMETER & $\begin{array}{c}\text { NORMAL WEIGHT } \\
(\mathbf{n}=\mathbf{3 0})\end{array}$ & $\begin{array}{c}\text { OVER WEIGHT } \\
(\mathbf{n}=\mathbf{3 0})\end{array}$ & $\begin{array}{c}\text { OBESE } \\
(\mathbf{n}=\mathbf{3 0})\end{array}$ & P value \\
\hline Before exercise & & & & \\
SBP $(\mathrm{mm} \mathrm{Hg})$ & $106.32 \pm 8.41$ & $110.43 \pm 8.39$ & $115.86 \pm 9.10+$ & $<0.001$ \\
DBP $(\mathrm{mm} \mathrm{Hg})$ & $66.38 \pm 6.21$ & $75.65 \pm 6.78^{*}$ & $80.13 \pm 7.69+$ & $<0.001$ \\
At exhaustion & & & & \\
SBP $(\mathrm{mm} \mathrm{Hg})$ & $135.80 \pm 10.01$ & $149.02 \pm 12.67 *$ & $155.76 \pm 14.70 \dagger$ & $<0.001$ \\
DBP (mm Hg) & $68.41 \pm 4.96$ & $67.23 \pm 6.38$ & $65.36 \pm 8.31$ & 0.210 \\
\hline
\end{tabular}

The level of significance was set at $p<0.05$

Values expressed as Mean \pm SD

*Significantly different between normal and overweight group

+ Significantly different between normal and obese group

$¥$ §ignificantly different between overweight and obese group

sympathetic response [15]. There is also an increased activity of renin angiotensin aldosterone system. The diastolic blood pressure at exhaustion reduced more than normal weight group. However, this reduction was not significant. This could be attributed to decreased exercise tolerance of participants in study groups. This study is limited to small group of participants and only males were included in the study. Therefore, a gender variation of blood pressure response to $\mathrm{BMI}$ at peak exercise requires confirmation utilizing larger group.

\section{CONCLUSION}

This study shows that there is a significant exacerbation of blood pressure response to peak exercise in obese when compared to normal weight participants suggesting greater reactivity to physical exertion. This exacerbated response could be related to metabolic and autonomic abnormalities that usually precede the establishment of hypertension. As a result peak exercise can be utilized in early detection of risk of development of cardiovascular diseases in obese young males.

\section{Conflicts of interest: None}

\section{REFERENCES}

1. Manojan KK, Benny PV, Anil Bindu. Prevalence of obesity and overweight among medical students based on New Asia-Pacific BMI guideline. IJPTM 2014; Volume $1 . \quad$ Available from: http://ijptm.com/index.php/ijptm/article/view/196.

2. Selvaraj K, Sivaprakasam P. A study on the prevalence of overweight and obesity among medical students of Kanchipuram district. NJRCM 2013;2(2):140-4. Available from: http://commedjournal.in/cur.html.
3. Jayaraj, PP Nair et al. Prevalence of Overweight and Obesity Among Students of a Medical College in South India: A Pilot Study. Indian Journal of Clinical Practice 2014; 5(4): 333-337. Available from: https://issuu.com/ijcp2/docs/indian-journal-ofclinical-practice_741ec7fb1a3094.

4. Montani J-P, Antic V, Yang Z, Dulloo A. Pathways from obesity to hypertension: from the perspective of a vicious triangle. International Journal of Obesity. 2002 Aug 15;26(s2):S28-S38. Available from: http://dx.doi.org/10.1038/sj.ijo.0802125.

5. Aldo Ferrara L, Palmieri V, Limauro S, Viola S, Palmieri $E A$, Arezzi E, et al. Association between post-ischemic forearm blood flow and blood pressure response to maximal exercise in well trained healthy young men. International Journal of Cardiology*. 2006 Aug;111(3):394-8. Available from: http://dx.doi.org/10.1016/j.ijcard.2005.08.011.

6. Valensi P, Bich Ngoc PT, Idriss S, Paries J, Cazes P, Lormeau $B$, et al. Haemodynamic response to an isometric exercise test in obese patients: Influence of autonomic dysfunction. International Journal of Obesity. 1999 May 26;23(5):543-9. Available from: http://dx.doi.org/10.1038/sj.ijo.0800873.

7. Diwan SK, Nikhil Jaiswal et al. Blood pressure response to Treadmill testing among Medical graduates : The Right time to Intervene. Indian Heart Journal. 2005; 57: 237-240. Available from: http://indianheartjournal.com/pdf/May\%20June2005 .pdf.

8. R. Rajalakshmi et al. Blood pressure responses to steady treadmill exercise in overweight and obese young adults. Indian J Physiol Pharmacol. 2011; 55 (4): 309-314. Available from: http://www.ijpp.com/IJPP\%20archives/2011_55_4/3 09-314.pdf. 
9. i goveronment_in.mht, India reworks obesity guidelines, BMI lowered, Published on 11/26/200812:40:52 PM, accessed at 9.00 p.m. on $17 / 11 / 2009$. Available from:

http://www.igovernment.in/articles/26259/indiareworks-obesity-guidelines-bmi-lowered.

10. Gibbons RJ. ACC/AHA Guidelines for exercise testing. A report of the American College of Cardiology/American Heart Association Task Force on practice guidelines (Committee on Exercise Testing). J Am Coll Cardiol 1997;30:260-315. Available from: http://www.sciencedirect.com/science/article/pii/so 735109797001502.

11. Bruce RA. Exercise Testing Methods and Interpretation. Cardiac Rehabilitation. 6-15. Available from: http://dx.doi.org/10.1159/000401440

12. Mohan B, Kumar N, Aslam N, Rangbulla A,Kumbkami $S$, Sood NK, et al. Prevalence of Sustained Hypertension and Obesity in Urban and Rural School Going Children in Ludhiana Indian Heart J. 2004 Jul-
Aug;56(4):310-4. Available from: http://www.ncbi.nlm.nih.gov/pubmed/15586739.

13. Rao S, Kanade A, Kelkar R. Blood pressure among overweight adolescents from urban school children in Pune, India. Eur J Clin Nutr 2007; 61: 633-641. Available from: http://www.nature.com/ejcn/journal/v61/n5/pdf/16 02555a.pdf?origin=publication_detail.

14. Esler M, Straznicky N, Eikelis N, Masuo K, Lambert G, Lambert E. Mechanisms of Sympathetic Activation in Obesity-Related Hypertension. Hypertension. 2006 Sep 25;48(5):787-96. Available from: http://dx.doi.org/10.1161/01.hyp.0000242642.42177 .49 .

15. Carletti L, Rodrigues AN, Perez AJ, Vassallo DV. Resposta da pressão arterial ao esforço em adolescentes: influência do sobrepeso e obesidade. Arquivos Brasileiros de Cardiologia. 2008 Jul;91(1):25-30. Available from: http://dx.doi.org/10.1590/s0066-

$782 \times 2008001300004$ 